\title{
On the coastal erosion risk assessment indexes
}

\author{
Lifen Xu \\ College of Urban and Environmental Sciences \& Laboratory for Earth Surface Process of Ministry of \\ Education, Peking University, Beijing 100871; \\ National Marine Environment Monitoring Center, Dalian 116023 \\ Shiyong Wen, Dongzhi Zhao \\ National Marine Environment Monitoring Center, Dalian 116023 \\ Xuegong Xu \\ College of Urban and Environmental Sciences \& Laboratory for Earth Surface Process of Ministry of \\ Education, Peking University, Beijing 100871 \\ Received 6 September 2013 \\ Accepted 18 October 2013
}

\begin{abstract}
China is one of the most severely affected countries by coastal erosion. About $70 \%$ of the sandy beaches and most of muddy tidal flat in open water regions are erode. Coastal erosion results in the width of beach being narrowed, bathing beach destruction, coast-protection facilities and roads collapse, and wetland deterioration. These destructions bring many losses to the local people. However, previous coastal erosion studies focused on the hazard of erosion and paid less attention to the risk of erosion. Therefore, it's necessary to study the mechanism of coastal erosion and build the coastal erosion risk assessment system for the effective coastal management. On the basis of the existed researches, this paper builds the coastal erosion risk assessment index system which contains hazard index system and vulnerability index system. The index system is expected to provide a practical theoretical basis for coastal erosion risk assessment.

Keywords: Coastal erosion, risk assessment, index
\end{abstract}

\section{海岸侵蚀灾害风险评估指标体系研究}

\author{
徐丽芬 ${ }^{1,2}$, 文世勇 ${ }^{2}$, 赵冬至 ${ }^{2, *}$, 许学工 ${ }^{1}$ \\ 1. 北京大学城市与环境学院 地表过程与模拟教育部重点实验室, 北京 100871 \\ 2. 国家海洋环境监测中心, 辽宁 大连 116023
}

\begin{abstract}
摘要
我国是海岸侵蚀灾害最严重的国家之一, 约有 $70 \%$ 的砂质海滩和大部分处于开阔水域的泥质 潮滩受到侵蚀。海岸侵蚀使得海滩劣化、浴场破坏、湿地损失、堤坝倒塌等, 给沿岸地区的生 产、人们生活造成损失。以往的研究主要关注海岸侵蚀灾害的损失; 从风险评估角度开展海岸 侵蚀研究还少见报道, 国内外在此方面的研究也相对薄弱。系统全面地认识海岸侵蚀灾害的影 响因素、作用机理、发生过程及其危害, 建立海岸侵蚀灾害风险评估指标体系, 是海岸侵蚀灾 害风险评估的理论基础。本文主要基于大量的文献, 提取相关研究方案中的指标参数, 构建海 岸侵蚀灾害风险评估指标体系。指标体系中包含致灾因子的危险性指标以及承灾体易损性指标。
\end{abstract} 关键词: 海岸侵蚀, 风险评估, 指标体系

\footnotetext{
*通讯作者, E-mail: dzzhao@nmemc.gov.cn 基金项目: 国家海洋局业务工作海洋灾害监测、预警与预报; 国家自然科学基金项目（NO.41271102, 40830746)
} 


\section{1 引言}

海岸侵蚀（coastal erosion）指在海洋动 力作用下, 导致海岸线向陆迁移或潮间带滩 涂和潮下带底床下蚀的海岸变化过程 ${ }^{[1]}$ 。狭 义的海岸侵蚀仅指自然海岸的侵蚀后退过 程; 广义的海岸侵蚀不仅包括自然海岸的蚀 退, 而且包括人工海岸的破坏过程 ${ }^{[2]}$ 。我国 海岸变化经历了整体淤进或稳定 (1950s 之 前）——局部侵蚀 (1950s-1970s) ——普遍 侵蚀（1970s 之后）的发展过程 ${ }^{[1]}$ 。据统计, 约有 $70 \%$ 的砂质海滩和大部分处于开阔水 域的泥质潮滩受到侵蚀 ${ }^{[3]}$ 。各海域沿岸侵蚀 岸线占总岸线的比例: 在渤海沿岸为 $46 \%$, 黄海沿岸为 $49 \%$, 东海沿岸 (包括台湾岛) 为 $44 \%$, 南海沿岸 (包括海南岛) 为 $21 \%{ }^{[4]}$ 。 海岸侵蚀使得海滩劣化、浴场破坏、湿地损 失、堤坝倒塌等, 给沿岸地区的生产和人民 财产带来损失。以往的海岸侵蚀防治主要采 用硬工程措施以防堵为主, 虽有立竿见影之 效, 但也为将来埋下隐患。系统全面地认识 海岸侵蚀灾害的影响因素、作用机理、发生 过程及其危害, 建立海岸侵蚀灾害风险评估 体系，对海岸综合管理具有重要意义 ${ }^{[5]}$ 。

目前, 绝大多数研究成果集中于海岸侵 蚀现状 ${ }^{[3,6-18]}$ 、原因 ${ }^{[2,4,19-29]}$ 以及未来预测分 析 ${ }^{[30-42]}$ 。少数研究从灾害风险评估视角对海 岸侵蚀开展研究, 如张晓龙等定性分析了黄 河三角洲在海面上升、风暴潮、黄河断流等 灾害风险因素作用下, 黄河三角洲海岸侵蚀 将加剧, 滨海湿地将损失和退化, 而没有进 行定量的风险评估 ${ }^{[5]}$; 王文海等就海岸侵蚀 灾害本身进行评估, 提出采用经济总损失 量、单位岸线损失量、人均损失量、国民生 产总值损失率、国民收入损失率、预算内收 人损失率、受灾率和土地损失率等指标作为 评估参数, 将海岸侵蚀灾害分为特大灾、大 灾、中灾、小灾和轻灾五种 ${ }^{[43]}$ 。Del Río 以 及 Kane 等对海岸侵蚀灾害进行风险评估, 建立了包含 11 个自然因素 (危险性指数) 和 6 个社会经济要素 (承灾体的影响指数) 的指标体系, 并对各指标进行分级, 最终采 用加权平均的方法进行综合评价, 给出风险 值 ${ }^{[42,44]}$ 。Domínguez 通过收集 1956，1977,
1984，1989，1992，1994，2001 等 7 期航片, 分析西班牙西南岸的易损性。首先通过校正 影像, 用断面法分析岸线后退速率; 其次, 将海岸按使用类型分为四类——高密度建 筑区, 零星建筑区, 农用区, 自然区; 最后, 综合分析岸线后退速率与海岸使用类型确 定海岸的易损性，将易损性分为五级 ${ }^{[45]}$ 。

然而, 这些风险评估多侧重于某一方 面, 或侧重致灾因子的危险性评价 ${ }^{[5]}$, 或侧 重承灾体的易损性评价 ${ }^{[43]}$ 。Domínguez 的研 究虽然综合考虑了危险性和易损性, 但其危 险性仅仅根据历史岸线后退速率而定，未考 虑其他相关因素。本文拟综合考虑致灾因子 的危险性以及承灾体的易损性, 构建海岸侵 蚀灾害风险评估指标体系。研究方法主要基 于大量的文献, 提取相关研究方案中的指标 参数予以综合。

\section{2 海岸侵蚀灾害风险评估内涵}

不同的学者对灾害风险的认识和表达 有一定的差异。IPCC 的报告指出风险是灾 害发生概率与其对承灾体影响程度的乘积

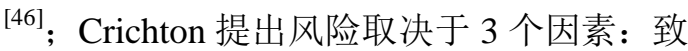
灾因子、脆弱性和暴露性 ${ }^{[47]}$ 。联合国指出风 险是致灾因子、脆弱性和恢复力的函数 ${ }^{[48]}$ 。 但无论以何种方式表达, 灾害风险的最核心 的含义即为:

$$
R=f(H, V)
$$

式中, $R$ 为海岸侵蚀风险; $H$ 为海岸 侵蚀的致灾因子发生的概率, 即危险度; $V$ 为承灾体易损度, 即暴露在海岸侵蚀风险中 的各种要素自身遭受侵蚀的可能损失。

海岸侵蚀灾害风险指海岸侵蚀灾害发 生的可能性及其可能造成的损失 ${ }^{[49]}$ 。依据海 岸侵蚀灾害分析评估的内涵, 可知海岸侵蚀 灾害风险评估指标体系应包括海岸侵蚀灾 害危险度评估指标与承灾体易损度评估指 标。此外, 海岸侵蚀灾害相较于其他灾害, 有一定的特殊性。海岸作为一个侵蚀对象的 同时, 它还是承载其他承灾体的载体。因此, 在评估其风险时, 应首先考虑海岸本身的性 质。海岸性质的不同决定着海岸侵蚀分布格 
局的不同。在此主要体现在海岸类型上, 不 同的海岸类型, 遭受侵蚀的可能性不一样, 海岸类型控制着海岸侵蚀空间分布规律。海 岸类型大体上可分为: 砂 (砾) 质海岸、基 岩海岸、淤泥质海岸、生物海岸、人工海岸。 在我国, 总体来说, 以砂质海岸侵蚀最为明 显, 且疏松的砂质海岸较砾质海岸抗侵蚀能 力差。基岩海岸的蚀退速率很小。淤泥质岸 段侵蚀不明显。人工岸段基本保持稳定。在 风险评估实践中, 评估指标值会因海岸类型 的不同而有所差异。因此, 在具体实施海岸 侵蚀风险评估时, 需在评估指标的基础上, 对每一类型的海岸进行分别评估。

\section{3 海岸侵蚀灾害危险度评估指标}

\section{1 影响海岸侵蚀灾害危险度的主要}

\section{因子}

造成我国海岸侵蚀灾害的原因多种多 样, 但基本可归纳为自然因素和人为因素两 大类。其中, 自然因素包括: 风暴潮、海浪 侵袭, 海平面上升, 河流输沙减少; 人为因 素包括: 海岸采砂, 河流水利工程拦截泥沙, 海岸工程加强了水动力, 海滩植被的破坏 等。而在这些影响因素中, 风暴潮、海浪, 海平面上升, 河流入海泥沙量减少, 人类活 动四个方面是造成海岸侵蚀最主要的因素。

\subsection{1 风暴潮、海浪}

在近岸, 风暴潮和海浪这两个过程并存 并且相互影响。在此, 将两个过程统一成一 个因素来看待。实际上, 风暴潮、海浪等对 海岸侵蚀的作用可理解为离岸输沙作用, 即 通过海岸增水形成强大的垂直环流或侵蚀 性裂流, 把波浪掀起的泥沙和本身侵蚀的底 沙带到离岸很远的深处堆积下来或被潮流 带走 ${ }^{[30]}$ 。有时候一次强风暴造成的侵蚀量甚 至超过正常天气下全年的侵蚀量, 如 1992 年的 9216 号强热带风暴致使山东境内的砂 质海岸后退 3-12m, 最大达 $30 \mathrm{~m}^{[50]}$ 。

风暴潮引起的海岸侵蚀量, 通常用侵蚀 的沉积物体积来表达或者用岸线后退的距
离来表达。对于侵蚀的沉积物体积, 往往采 用波浪、海流等的输沙理论予以计算。由于 侵蚀体积的大小与波浪的冲刷力呈正相关

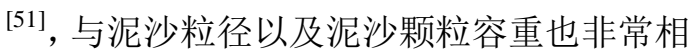
关 ${ }^{[58]}$ 。从构建的定量计算公式看, 很多研究 表明风暴潮影响下海滩离岸输沙量 $\Delta V$ 与 Dean 参数相关, 其中 Dean 参数是浪高、泥 沙沉积速率以及风暴持续时间的函数 ${ }^{[52-56]}$ 。

而 Larson 等人在借鉴已有研究结果的基础 上, 推出海岸侵蚀体积的定量计算公式, 认 为侵蚀体积是海滩坡度、沙丘高度、波浪爬 高、持续时间等的函数 ${ }^{[57]}$ 。Mendoza 等人使 用波高、波周期、风暴持续时间、泥沙粒径 以及岸滩坡度等因素来预测风暴潮对海滩 的侵蚀 ${ }^{[54]}$ 。

相对于侵蚀体积的计算, 用岸线后退距 离表达的海岸侵蚀量虽然不乏公式的定量 计算, 但更多的是基于统计建立的经验关 系。Kriebel 等通过长期对 Delaware 附近海 岸剖面观察和测量, 提出了风暴潮造成海岸 线后退的经验公式, 认为风暴潮引起的岸线 后退是近岸波高、风暴增水以及风暴持续时 间的函数 ${ }^{[59]}$ 。Jiménez 等提出用有效波高和 最大波高对应的周期来表达风暴潮触发的 海岸侵蚀潜在指数 ${ }^{[55]}$ 。Cooper 等提出风暴 潮对海滩的影响是风暴潮持续时间、风速、 风向综合作用的结果 ${ }^{[60]}$ 。

综合上述分析，风暴潮、海浪等对海岸 侵蚀的指标至少应包含: 波高、最高波浪周 期、平均波向、风浪持续时间、波浪方向频 率等。

\subsection{2 海平面上升}

海平面上升与长期的海岸侵蚀速率有 关, 而且其影响是整体性和缓变性的。海平 面上升对海岸的侵蚀作用, 主要是由于加大 的水深使波浪对古海岸的扰动作用减小致 使海底的横向供沙减少, 却加强了激浪对上 部海滩的冲刷而造成的 ${ }^{[20]}$ 。

在定量计算海平面上升引起的海岸线 后退量的研究中, Bruun 法则 ${ }^{[61]}$ 应用最多。 Bruun 法则是基于以下假设得出的: 海平面 上升过程中, 海岸均衡剖面向岸和向上移 动, 从而造成海滩侵蚀和滨外浅水区堆积; 
海滩的侵蚀物沉积在滨外浅水区, 侵蚀和堆 积的沉积物数量相近; 滨外浅水区的沉积厚 度与海平面上升值相等, 从而维持了海岸均 衡剖面不变 ${ }^{[62]}$ 。所以 Bruun 法则的适用对象 为有明显的相对海平面上升, 均匀的砂质沉 积物, 沉积物的数量变化较小的砂质海岸。 在这种条件下, 岸线后退速率与相对海平面 相对速率呈正相关，与岸滩坡度呈负相关。 王颖等对 Bruun 图进行了修正 (图 1), 认为 相对海平面上升导致的海岸线后退量由两 部分组成: 因海平面上升使部分海滩受淹没 而产生的后退量 (图 1 中的 $\Delta x_{1}$ ) 以及相对
海平面上升而造成的海滩侵蚀后退量（图 1 中的 $\left.\Delta x_{2}\right)^{[20]}$ 。其研究结果表明：相对海平 面上升 $0.5 \mathrm{~m}$ ，大连、秦皇岛、青岛、北海、 三亚海滩滨线将分别平均后退 $39.6 \mathrm{~m}$ 、 $36.7 \mathrm{~m} 、 28.0 \mathrm{~m} 、 22.5 \mathrm{~m} 、 13.1 \mathrm{~m}$ 。不仅对于砂 质海岸, 相对海平面上升与岸线后退存在这 种关系, 基岩海岸与相对海平面上升之间也 存在一个类似的较共通的关系, 即相对海平 面上升速率与岸线后退速率呈正相关 ${ }^{[63]}$ 。

通过上述分析可以看出, 在衡量海平面 与海岸侵蚀的关系中, 相对海平面上升高度 (速率)、海滩近滨坡度是关键指标。

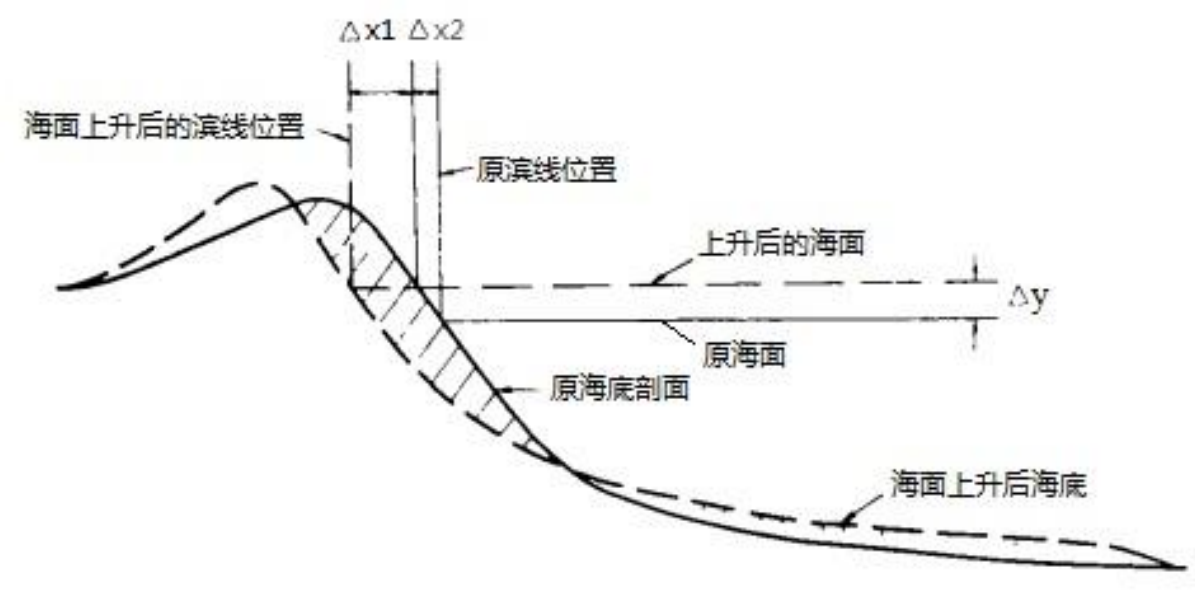

(图中假定海面上升前后的海滩剖面均已达到平衡, $\Delta y$ 为海面上升幅度)

图1 修正后的Bruun图 ${ }^{[20]}$

Fig.1 The revised diagrammatic sketch of Bruun rule ${ }^{[20]}$

\subsection{3 河流入海泥沙量}

河流入海泥沙量是影响海岸侵蚀的最 重要原因。近三四十年来, 中国沿岸河流入 海泥沙量减少了一半以上, 由入海泥沙 $20 \times 10^{8} \mathrm{t} / \mathrm{a}$ 减为不足 $10 \times 10^{8} \mathrm{t} / \mathrm{a}$, 造成我国海 岸泥沙收支严重失衡, 使得部分海岸由淤积 为主, 转为以侵蚀为主 ${ }^{[1]}$ 。

虽然很多研究定性分析了河流入海泥 沙量的减少是造成海岸侵蚀的重要原因, 但 是定量刻画河流入海泥沙量与岸线后退之 间的关系却少见报道。河流入海泥沙量只是 一个河口断面的泥沙含量值, 而泥沙入海后 一部分沉积在河口及沿岸, 一部分则被潮 汐、海流扩散输送到近海沉积 ${ }^{[64]}$ 。真正对岸 线塑造起作用的是在河口及沿岸沉积的部
分。泥沙入海之后, 到底多大的比例是沉积 在河口及沿岸, 却无法单纯从河流入海泥沙 量这个指标得出。所以急需找到一个监测入 海后泥沙含量的指标。悬浮泥沙含量是一个 综合因素, 它不仅受到河流入海泥沙量、海 岸工程的影响, 而且也会受到风暴潮、海浪、 海平面上升等因素的影响, 海流是输沙的主 要动力, 风浪 (包括风暴潮) 是掀沙的主要 动力。但悬浮泥沙的主要来源是径流 ${ }^{[65]}$ 。 秦蕴珊等将悬浮泥沙含量近似地看作平均 输沙率, 根据河流入海泥沙量、近河口浅海 区某一断面上的输沙量, 推测两断面之间的 冲淤率, 即入海泥沙对海岸塑造的影响 ${ }^{[6]}$ 。

由此可以认为对比分析河流入海泥沙 量、悬浮泥沙含量以及沿岸流的输沙率，可 
得到河口及沿岸的泥沙平衡, 进而建立泥沙 平衡与岸线后退速率的关系。

\subsection{4 人类活动}

在影响海岸侵蚀的人类活动中, 人工采 砂对海岸侵蚀造成的影响最为直接和显著。

因建筑上的要求, 人们在海岸地区的海 滩、河口和水下采砂, 造成海岸泥沙亏损, 打破岸滩剖面平衡, 造成侵蚀。采砂活动对 岸线的影响是迅速而且非常剧烈的。据初步 统计, 仅 1992 年 4 7 月辽东湾滕房身至田 家崴子一带海滩采砂就达 40 万 $\mathrm{t}$, 使这一带 近百米的沙滩消失 ${ }^{[21]}$ 。

因此, 人工采砂量是需要考虑的指标。

\section{2 海岸侵蚀灾害危险度评估指标体 系的建立}

根据上述分析, 将风暴潮、海浪, 海平 面上升, 河流入海泥沙量以及人类活动这四 大因素根据要素属性解析为如下指标, 如表 1 所示。
表 1 中的指标与海岸侵蚀的关系, 可以 定性描述如下: 流速、水深、泥沙颗粒容重、 泥沙粒径是近滨的水文泥沙条件, 决定着水 流挟沙能力。若将风暴潮、波浪等对海岸侵 蚀的作用理解为离岸输沙, 则水流挟沙能力 越强, 海岸侵蚀的可能性则越大。波高、波 向以及波周期是描述海浪特征的重要指标。 其中, 波高与海浪的能量有关, 浪越高, 表 明海浪的能量越大, 对海岸侵蚀的潜在破坏 力也越大 ; 波向决定着海岸侵蚀的展布方 向; 波周期与海浪的频率有关, 频率越高, 侵蚀的可能性也越大。风暴增水值是衡量风 暴能量的重要因素, 风暴潮增水值越大, 表 明风暴潮所蕴含的能量越高, 风暴潮对海岸 侵蚀的可能性越大。风暴潮持续的时间也是 影响海岸侵蚀程度的重要因素, 持续时间越 长, 侵蚀的程度将会越大。海平面上升高度 越大, 岸线后退量也越大; 相反, 近滨坡度 越大, 岸线后退量越小。人工采砂量越大, 对海岸侵蚀的影响也越大。

表 1 海岸侵蚀危险度评估指标与编码

Table 1 Coastal erosion hazard indexes and codes

\begin{tabular}{cccc}
\hline $\begin{array}{c}\text { 影响因素层 (I 级) } \\
\text { 名称 }\end{array}$ & 编码 & 要素指标层 (II 级) & 编码 \\
\hline 风暴潮、海浪 & & 风暴增水 & $\mathrm{H} 11$ \\
& $\mathrm{H} 1$ & 风暴潮持续时间 & $\mathrm{H} 12$ \\
& & 浪高 & $\mathrm{H} 13$ \\
& & $\mathrm{H} 14$ \\
海平面上升 & $\mathrm{H} 2$ & 波浪方向频率 (或平均波向) & $\mathrm{H} 21$ \\
& & 最大波浪周期 & $\mathrm{H} 22$ \\
& & 相对海平面上升高度 & $\mathrm{H} 31$ \\
& & 海滩近滨坡度 & $\mathrm{H} 32$ \\
河流入海泥沙 & 流速 & $\mathrm{H} 33$ \\
& $\mathrm{H} 3$ & 流向 & $\mathrm{H} 34$ \\
& & 水深 & $\mathrm{H} 35$ \\
& & 泥沙粒径 & $\mathrm{H} 36$ \\
& $\mathrm{H} 4$ & 河流入海泥沙量 & $\mathrm{H} 41$ \\
\hline
\end{tabular}




\section{4 承灾体易损度评估指标}

\section{1 承灾体范围的确定}

承灾体是海岸侵蚀影响区内的土地以 及附着在其上的生态系统、建设在该区域内 的一切设施如港口码头、房屋、娱乐设施等。 虽然海岸侵蚀的影响范围会因不同类型的 岸段而有所差异, 侵蚀后退量多则上百米, 少则几厘米。

根据陈吉余等 ${ }^{[1]}$ 制定的海岸侵蚀强度 等级标准, 年均侵蚀速率在 1 2m/a 的砂质 海岸即为强侵蚀。从海岸工程的设计标准为 50 年一遇至 100 年一遇的情景看, 调查范围 距海岸线 $200 \mathrm{~m}$ 范围即可。考虑到滨海公路 作为承灾体的同时也是海岸侵蚀的人工阻 隔物 (尤其对滨岸的公路), 因此在有距岸 线较近的区域内, 以滨海公路向海一侧为承 灾体的调查范围。而对于基岩海岸, 由于它 的侵蚀速率非常低, 统一规定以 $200 \mathrm{~m}$ 为界, 有失偏颇, 故在此以高程低于 $10 \mathrm{~m}$ 来给出 调查范围。
综合这些分析，提出以下两条承灾体调 查范围划定方案:

(1) 距海岸线 $200 \mathrm{~m}$ 之内（辽东湾以滨 海路向海一侧为界)

（2）以高程低于 $10 \mathrm{~m}$ 为界（在基岩海 岸区, 海岸侵蚀基本影响不到距水边线 $200 \mathrm{~m}$ 左右的区域, 此情景下可以采用高程 条件来进行调查范围的划定)。

\section{2 承灾体因子分类体系的确定}

制定合理的海岸侵蚀承灾体分类体系 是承灾体易损度的基础。海岸侵蚀承灾体的 分类主要遵循以下原则:

（1）完整性。海岸侵蚀所影响到且会 受到损失或破坏的地物类型均需包含在内。

（2）可量化。承灾体分类是为易损性 评价做准备, 因此, 承灾体需易于量化, 以 便于下一步的承灾体易损性评价。

依照上述原则, 在参考大量相关文献材 料的基础上, 结合海岸侵蚀灾害的危害特 点, 确定了海岸侵蚀灾害承灾体因子及分类 体系编码等, 为开展海岸侵蚀灾害承灾体易 损度评估奠定基础。

表 2 海岸侵蚀承灾体分类与编码

Table 2 Classifications and codes of coastal erosion risk receptors

\begin{tabular}{|c|c|c|c|c|c|}
\hline \multicolumn{2}{|l|}{ 一级 } & \multicolumn{2}{|l|}{ 二级 } & \multicolumn{2}{|c|}{ 三级 } \\
\hline \multirow[t]{2}{*}{ 名称 } & \multirow[t]{2}{*}{ 编码 } & 名称 & 编码 & 名称 & 编码 \\
\hline & & 简易房 & A11 & & \\
\hline \multirow{5}{*}{ 建筑物 } & \multirow{3}{*}{ A1 } & 平房 & $\mathrm{A} 12$ & & \\
\hline & & 多层楼房 & $\mathrm{A} 13$ & & \\
\hline & & 高层楼房 & $\mathrm{A} 14$ & & \\
\hline & \multirow{6}{*}{ A2 } & & & 土堤 & A211 \\
\hline & & 防波堤 & $\mathrm{A} 21$ & 混凝土堤 & A 212 \\
\hline \multirow[t]{5}{*}{ 港口设施 } & & & & 砌体堤 & A213 \\
\hline & & 码头泊位 & $\mathrm{A} 22$ & & \\
\hline & & 仓库 & A23 & & \\
\hline & & 高速公路 & $\mathrm{A} 31$ & & \\
\hline & \multirow{4}{*}{$\mathrm{A} 3$} & & & 国道 & A 321 \\
\hline \multirow[t]{3}{*}{ 交通设施 } & & 一般公路 & A32 & 省道 & A 322 \\
\hline & & & & 乡村道路 & A 323 \\
\hline & & 铁路 & A33 & & \\
\hline \multirow[t]{3}{*}{ 工矿类 } & \multirow[t]{3}{*}{ A4 } & 盐田 & A41 & & \\
\hline & & & & 海堤 & A511 \\
\hline & & 海岸防护工程 & A51 & 护岸 & A512 \\
\hline \multirow[t]{3}{*}{ 海岸防护工程及水工设施 } & \multirow[t]{3}{*}{ A5 } & & & 保滩设施 & A513 \\
\hline & & 水丁设施 & $\Delta 52$ & 闸坝 & A521 \\
\hline & & & A 2 & 排水口 & A522 \\
\hline
\end{tabular}




\begin{tabular}{|c|c|c|c|c|c|}
\hline & & & & 取水口 & A523 \\
\hline \multirow{3}{*}{ 养殖类 } & \multirow{3}{*}{ A6 } & 鱼塘虾池 & A61 & & \\
\hline & & 海养育苗室 & A62 & & \\
\hline & & 海滩浴场 & A71 & & \\
\hline \multirow[t]{6}{*}{ 旅游类 } & \multirow[t]{2}{*}{ A7 } & 旅游设施 & A72 & & \\
\hline & & 滨海公园 & A73 & & \\
\hline & & 农地 & $\Delta 81$ & 水田 & A811 \\
\hline & & 地 & AO1 & 旱地 & A812 \\
\hline & & & & 乔木 & A821 \\
\hline & & 林地 & A82 & 灌木 & A822 \\
\hline \multirow[t]{5}{*}{ 农林生态类 } & A8 & & & 园地 & A823 \\
\hline & & & & 苇地 & A831 \\
\hline & & 草地 & A83 & 荒草地 & A832 \\
\hline & & & & 人工草地 & A833 \\
\hline & & 滩涂湿地 & A84 & & \\
\hline
\end{tabular}

由于海岸侵蚀是缓发灾害。它对承灾体 的损坏, 不同于其他一些突发性的灾害如地 震、洪水那般瞬间摧毁性质。海岸侵蚀不至 于造成人员伤亡, 因此承灾体的分类表中没 有考虑人口分布指标。

\section{3 承灾体易损度评估指标体系}

海岸侵蚀造成的承灾体损失主要包括 两部分: 土地损失和经济损失。土地损失体 现在由于岸线后退造成如耕地、草地、湿地 等的减少。经济损失主要体现在海岸侵蚀造 成房屋倒塌、报废; 公路、海岸防护工程、 码头、港池等的损坏、废弃; 粮食的减产; 海滩旅游承载力降低导致的收入减少; 以及 由于防止岸线后退投入的防护、加固费用, 城镇、村庄的搬迁费用等 ${ }^{[46]}$ 。

\section{表 3 海岸侵蚀承灾体易损度评估指标与编码}

Table 3 Vulnerability indexes and codes of coastal erosion risk receptors

\begin{tabular}{llll}
\hline \multicolumn{2}{l}{ 因素层 (I 级) } & \multicolumn{2}{l}{ 要素层 } \\
名称 & 编码 & 名称 & 编码 \\
\hline & & & \\
\hline 承灾体类型 & $\mathrm{V} 1$ & & \\
价值 & $\mathrm{V} 2$ & $\begin{array}{l}\text { 单位面积价值 } \\
\text { 暴露面积 }\end{array}$ & $\mathrm{V} 21$ \\
损失率 & $\mathrm{V} 2$ & & \\
\hline
\end{tabular}

衡量这些承灾体造成的可能损失即为 易损度。易损度的评估包含两个方面: 一为 承灾体遭受侵蚀损坏的程度有多大, 不同承 灾体, 其承灾能力、抗灾能力和救灾能力不 同, 可用损失率来表示; 二为各承灾体的价 值量, 在此以单位面积的货币量来表示。但 并非研究范围内所有的承灾体都会遭受损 失, 只有暴露在岸线后退影响范围内的面积 才是成灾面积, 因此还需加入暴露面积这一 指标。

$$
V=f\left(t_{p}, E, \lambda\right)
$$

整理成易损度评估指标如表 3 所示。

\section{5 结束语}

本文在参考现有研究成果的基础上, 根 据海岸侵蚀灾害风险评估的内涵, 建立了包 括海岸侵蚀灾害危险度和承灾体易损度的 海岸侵蚀灾害风险评估指标体系。通过分析 海浪、风暴潮、海平面上升、河流入海泥沙 量减少、人类活动等主要致灾因子与海岸侵 蚀的关系, 建立了相应的海岸侵蚀灾害危险 
度评估指标; 在承灾体的范围、分类的基础 上, 提出承灾体易损度评估指标。本文所构 建的海岸侵蚀灾害风险评估指标体系, 能为

\section{6 参考文献}

[1] 陈吉余, 夏东兴, 虞志英等, 中国海岸侵 蚀概要, (海洋出版社, 北京, 2010).

[2] 王文海, 吴桑云, 山东省海岸侵蚀灾害研 究, 自然灾害学报 (04) (1993) 60-66.

[3] 夏东兴, 王文海, 武桂秋等, 中国海岸侵 蚀述要, 地理学报 (05) (1993) 468-476.

[4] 季子修, 中国海岸侵蚀特点及侵蚀加剧 原因分析. 自然灾害学报 (02)(1996) 69-79.

[5] 张晓龙与李培英, 黄河三角洲滨海湿地 海岸侵蚀灾害及风险, 应用基础与工程 科学学报 14(S1) (2006) 247-252.

[6] Davidson-Arnott and R.G.D.,J. Ollerhead, Nearshore erosion on a cohesive shoreline, Marine Geology122(4) (1995) 349-365.

[7] 苗丰民, 李淑媛, 符文侠等, 辽东湾东部 砂岸的近期变化及演变趋势, 海洋学报 (中文版) (02) (1996)74-84.

[8] List, J.H., A.H. Sallenger Jr.,M.E. Hansen, et al., Accelerated relative sea-level rise and rapid coastal erosion: testing a causal relationship for the Louisiana barrier islands, Marine Geology 140(3-4) (1997) 347-365.

[9] 王玉广, 李淑媛, 苗丽娟, 辽东湾两侧砂 质海岸侵蚀灾害与防治, 海岸工程 (01) (2005) 9-18.

[10] Andriani, G.F. and N. Walsh, Rocky coast geomorphology and erosional processes: A case study along the Murgia coastline South of Bari, Apulia - SE Italy, Geomorphology 87(3) (2007) 224-238.

[11] 王玉广, 张宪文, 贾凯等, 辽东湾绥中海 岸侵蚀研究, 海岸工程 (01) (2007) 1-5.

[12] 孔繁德, 秦皇岛市海岸侵蚀研究及防治 对策, 城市发展研究 (01)(2008)73-76.

[13] Jabaloy-Sánchez, A., F.J. Lobo, A. Azor, et al., Human-driven coastline changes in the Adra River deltaic system, southeast Spain,
海岸侵蚀风险评估提供借鉴和指导意义, 进 而促进海岸带的综合管理。

Geomorphology 119(1-2) (2010)9-22.

[14] 徐宗军, 张绪良, 张朝晖, 山东半岛和黄 河三角洲的海岸侵蚀与防治对策，科技 导报 (10) (2010)90-95.

[15] Cui, B., X. Li, Coastline change of the Yellow River estuary and its response to the sediment and runoff (1976-2005), Geomorphology 127(1-2) (2011)32-40.

[16] Liu, Y., H. Huang,Z. Qiu, et al., Detecting coastline change from satellite images based on beach slope estimation in a tidal flat, International Journal of Applied Earth Observation and Geoinformation 23(2013)165-176.

[17] 庄振业, 杨燕雄, 刘会欣, 环渤海砂质岸 侵蚀和海滩养护, 海洋地质前沿 (02)( 2013)1-9.

[18] Rahman, A.F., D. Dragoni, B. El-Masri, Response of the Sundarbans coastline to sea level rise and decreased sediment flow: A remote sensing assessment, Remote Sensing of Environment 115(12) (2011)3121-3128.

[19] 王文海, 我国海岸侵蚀原因及其对策, 海 洋开发 (01) (1987)8-12.

[20] 王颖, 吴小根, 海平面上升与海滩侵蚀, 地理学报 (02) (1995)118-127.

[21] 苗丰民，李光天,符文侠等，辽东湾东部 砂岸严重蚀退及其原因分析。海洋环境 科学 (01) (1996) 66-72.

[22] Budetta, P., G. Galietta, A. Santo, A methodology for the study of the relation between coastal cliff erosion and the mechanical strength of soils and rock masses, Engineering Geology 56(3-4) (2000)243-256.

[23] 丰爱平, 夏东兴, 谷东起等, 莱州湾南岸 海岸侵蚀过程与原因研究, 海洋科学进 展 (01) (2006) 83-90.

[24] 温倩, 方凤满, 高健, 山东半岛海岸侵蚀 成因及防治对策研究, 国土与自然资源 研究 (01) (2006)52-53. 
[25] 张晓龙, 李培英, 现代黄河三角洲的海岸 侵蚀及其环境影响, 海洋环境科学 (05) (2008)475-479.

[26] Brunel, C., F. Sabatier, Potential influence of sea-level rise in controlling shoreline position on the French Mediterranean Coast, Geomorphology 107(1-2) (2009) 47-57.

[27] HUANG, G., Time lag between reduction of sediment supply and coastal erosion, International Journal of Sediment Research 26(1) (2011) 27-35.

[28] 郭婷婷, 邵晓昕, 浅析海岸带侵蚀, 环境 保护与循环经济 (05) (2011) 37-39+59.

[29] Zhang, K.Q., B. Douglas, S. Leatherman, Do storms cause long-term beach erosion along the U.S. East Barrier Coast?, Journal of Geology 110(4) (2002) 493-502.

[30] 杨燕雄, 贺鹏起, 谢亚琮等, 秦皇岛海岸 侵蚀研究, 中国地质灾害与防治学报 (S1) (1994)166-170.

[31] 陈坚, 谢在团, 未来海平面上升对厦门海 滩侵蚀的测算, 台湾海峡 17(4) (1998)391-395.

[32] Leont'yev, I.O., Modeling erosion of sedimentary coasts in the western Russian Arctic, Coastal Engineering 47(4) (2003) 413-429.

[33] Brown, I., S. Jude,S. Koukoulas, et al., Dynamic simulation and visualisation of coastal erosion. Computers, Environment and Urban Systems 30(6) (2006) 840-860.

[34] Callaghan, D.P., P. Nielsen, A. Short, et al., Statistical simulation of wave climate and extreme beach erosion, Coastal Engineering 55(5) (2008) 375-390.

[35] 韩晓庆, 高伟明, 褚玉娟, 河北省自然状 态沙质海岸的侵蚀及预测, 海洋地质与 第四纪地质 (03)( 2008) 23-29.

[36] Callaghan, D.P., R. Roshanka, S. Andrew, Quantifying the storm erosion hazard for coastal planning, Coastal Engineering 56(1)(2009)90-93.

[37] Hapke, C. and N. Plant, Predicting coastal cliff erosion using a Bayesian probabilistic model, Marine Geology 278(1-4) (2010) 140-149.

[38] Trenhaile, A.S., Modeling cohesive clay coast evolution and response to climate change, Marine Geology 277(1-4) (2010) 11-20.

[39] Loureiro, C., Ó. Ferreira, J.A.G. Cooper, Extreme erosion on high-energy embayed beaches: Influence of megarips and storm grouping, Geomorphology 139-140(2012) 155-171.

[40] Ranasinghe, R., D. Callaghan, M.J.F. Stive, Estimating coastal recession due to sea level rise: beyond the Bruun rule, Climatic Change 110(3-4)( 2012) 561-574.

[41] Walkden, M.J.A. and J.W. Hall, A predictive Mesoscale model of the erosion and profile development of soft rock shores, Coastal Engineering 52(6)( 2005) 535-563.

[42] Kane, H.H., C.H. Fletcher, B.M. Romine, et al., Vulnerability Assessment of Hawai'i's Cultural Assets Attributable to Erosion Using Shoreline Trend Analysis Techniques, Journal of Coastal Research 28(3) (2012) 533-539.

[43] 王文海, 吴桑云, 陈雪英, 海岸侵蚀灾害 评估方法探讨，自然灾害学报 (01)( 1999) 71-77.

[44] Del Río, L. and F.J. Gracia, Erosion risk assessment of active coastal cliffs in temperate environments, Geomorphology 112(1-2) (2009) 82-95.

[45] Domínguez, L., G. Anfuso, F.J. Gracia, Vulnerability assessment of a retreating coast in SW Spain, Environmental Geology 47(8)(2005) 1037-1044.

[46] IPCC, Climate Change 2001: Impacts, Adaptation and Vulnerability, Summary for Policymakers, (2001)WMO.

[47] Crichton, D., The risk triangle. Natural Disaster Management, Tudor Rose, London, (1999)102-103.

[48] UN, Risk Awareness and Assessment in Living with Risk. ISDR,UN,WMO,Asian 
and

Disaster

Reduction

Center,Geneva(2002) 39-78.

[49]丰爱平, 夏东兴, 海岸侵蚀灾情分级, 海 岸工程(02)(2003) 60-66.

[50] 王文海, 吴桑云, 陈雪英, 山东省 9216 号 强热带气旋风暴期间的海岸侵蚀灾害, 海洋地质与第四纪地质 (04) (1994) 71-78.

[51] Overton, M.F., J.S. Fisher, K. Hwang, Development of a dune erosion model using SUPERTANK data, in Proceedings of $24^{\text {th }}$ International Conference on Coastal Engineering, Kobe, Japan, 1(24)(1994).

[52] Larson, M. and N.S. Kraus, SBEACH: Empirical Numerial Model for Simulating Storm-induced Beach Change, Report 1: Empirical foundation and model development, in Technical Report CERC-89-9 (US Army Corps of Engineers, Vicksburg, 1989)

[53] Wise, R.S., S.J. Smith, M. Larson, SBEACH: Numerical model for simulating storm-induced beach change, Report 4: cross shore transport under random waves and model validation with Supertank and field data, in Technical Report CERC-89-9 (US Army Corps of Engineers, Vicksburg, 1996)

[54] Mendoza, E.T. and J.A. Jiménez, Storm-induced beach erosion potential on the Catalonian coast, Journal of Coastal Research 48( S1) (2006)81-88.

[55]Jiménez, J.A., A. Sancho-García, E. Bosom, et al., Storm-induced damages along the Catalan coast (NW Mediterranean) during the period 1958-2008, Geomorphology 143-144(2012) 24-33.

[56] Jiménez, J.A. and A. Sánchez-Arcilla, Medium-term coastal response at the Ebro delta, Spain, Mar. Geol. 114 (1993)
105-118.

[57] Larson, M., L. Erikson, H. Hanson, An analytical model to predict dune erosion due to wave impact, Coastal Engineering 51(8-9) (2004) 675-696.

[58]Overton, M.F., W.A. Pratikto, J.C. Lu, et al., Laboratory investigation of dune erosion as a function of sand grain size and dune density, Coastal engineering 23(1) (1994)151--165.

[59] Kriebel, D., R. Dalrymple, A. Pratt, et al., A shoreline risk index for northeasters, in ASCE (1997), pp.251-252.

[60] Cooper, J.A.G., D.W.T. Jackson, F. Navas, et al., Identifying storm impacts on an embayed, high-energy coastline: examples from western Ireland, Marine Geology 210(1-4)( 2004) 261-280.

[61] Bruun, P., Sea-level rise as a cause of shore erosion, Journal of the Waterways and Harbors Division 88(1962) 117-130.

[62] 李从先，王平，范代读等，布容法则及其 在中国海岸上的应用，海洋地质与第四 纪地质 (01) (2000) 87-91.

[63] Ashton, A.D., M.J.A. Walkden, M.E. Dickson, Equilibrium responses of cliffed coasts to changes in the rate of sea level rise, Marine Geology 284(1-4) (2011)217-229.

[64] 程天文,赵楚年, 我国主要河流入海径流 量、输沙量及对沿岸的影响, 海洋学报( 中 文版) (04) (1985)460-471.

[65] 姜太良，房宪英,徐洪达等，河北省海岸 带浅滩海域悬浮泥沙输送的估算, 黄渤 海海洋 (03) (1986)94-103.

[66]秦蕴珊, 李凡, 渤海海水中悬浮体的研究, 海洋学报( 中文版) (02) (1982) 191-200.

[67] 冯金良, 人类工程活动对秦皇岛海滩侵 蚀及淤积的影响, 海岸工程 (03) (1997) 41-46. 